Send your letters to the Editor, British

Dental Journal, 64 Wimpole Street, London

W1G8YS E-mail bdj@bda.org

Priority will be given to letters less than 500

words long. Authors must sign the letter,

which may be edited for reasons of space.

\section{Out of date}

Sir, the General Dental Council has recently embarked on modernisation and radical change. There has been a new focus on continuing professional development to secure monitored contemporaneous practice and a move away from a democratically elected body to an appointed body in the cause of best patient protection. It was therefore concerning that in a recent professional conduct case the GDC's instructing solicitors used an expert witness who was well retired. Whilst it is of course for any tribunal to accept or discount in whole or part the evidence of an expert it does not match the modern standards expected of the profession to utilise retired professionals however illustrious the career of that expert may have been. At best a retired expert witness is beyond his or her sell-by-date medico-legally and at worst it represents either a poorly conceived case or an inadequately protected patient. Our regulating body can not absolve itself of responsibility to the public by giving its solicitors a free hand in this.

In modernising the profession's protection of the public should it not be the responsibility of the General Dental Council to instruct its own solicitors to use practising professionals as experts as a just and equitable way of discharging the council's own duty?

C. Holden

Chesterfield

\section{GDC Chief Executive and Registrar}

Duncan Rudkin responds: Thank you for giving me the opportunity to respond to this letter.

An essential part of our work is taking action to protect patients when there are concerns about a dental professional's skills, conduct or health. In his letter, Mr Holden highlights the significant reforms we have recently introduced to strengthen public protection, which include changes to our fitness to practise work. Your reader has raised a concern about the use of an expert witness in a recent Professional Conduct Committee case. I thought it would be helpful to explain how we select expert witnesses

for our fitness to practise work.

We always agree expert witnesses with our legal teams. An expert witness of any kind would never be used without our prior approval. Mr Holden is quite right about our responsibility for the choice made.

We rely on our legal support teams to recommend counsel and experts, in the light of their experience and on recommendation from others. Some of the factors which affect expert choice are:

- relevant subject area/knowledge

- known experience/performance in front of disciplinary panels

- availability

- whether there is a conflict of interests.

Some cases we investigate may involve events that occurred some time ago. In these cases, it can be appropriate to use experts whose knowledge was current at the time even though they may have recently retired.

After each Professional Conduct Committee hearing, we provide feedback to the relevant legal team on the performance of experts and counsel. We very rarely have problems with either counsel or experts but if there were issues about competence or performance, we would consider very carefully whether that person should be used again.

As expert witnesses are essential to our fitness to practise procedures we work very closely with our legal terms to ensure that these witnesses are appropriate for the specific case they are engaged in.

DOI: 10.1038/bdj.2007.695

\section{Poor CPD delivery}

Sir, I found your editorial regarding the $B D J$ CPD delivery (BDJ 2007; 202:

703-704) most patronising. You criticise the fact that members prefer paper to computers. This is not because we are technophobes. It is what is most convenient. It is easier to answer online as it is immediate and straightforward and makes record-keeping easier. However, online access to the articles is more complicated and I have wasted lots of

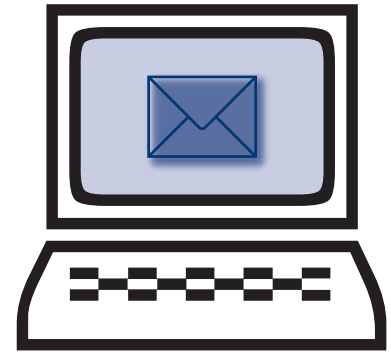

time just trying to access the articles, not always successfully. If you had made access as simple as answering the questions you would not have had the complaints.

I note, from your ivory tower, that you did not refer to these access problems in your article and admit no responsibility for poor delivery of the online CPD. I am all for change if it improves matters, but your online CPD has not done so. B. Soffair

By email

DOI: $10.1038 /$ bdj.2007.696

\section{Dumbing down}

Sir, I would like to express my concern about recent changes related to the publication of scientific articles by your journal. Scientific articles are now only available in full on the website, whilst a research summary is published in the journal itself. The research summary consists of the abstract, editor and reviewer comments and author questions and answers.

The effect of this is that the editor's summary and the comments are given more weight in the paper version of the journal than the article itself. This is despite the fact that the article has been through a review process but the comments have not. In addition the authors do not have the ability to address some of the points raised by the commentary; the overall effect being a potentially unbalanced view of the original research.

I believe that this is a 'dumbing down' of the journal and implies that your general readership cannot cope with or are not interested in scientific articles. I believe that this will have the effect of reducing the number of scientific contributions the journal receives and may affect the journal's rating and it is a retrograde decision by the journal which should be reviewed.

C. Drugan

Bristol

DOI: 10.1038/bdj.2007.697

\section{Broadening horizons}

Sir, I have been following the recent correspondence regarding the decision 
to make one of the papers for the $B D J$ CPD programme each month only available in full through an online format.

Although I attempt to achieve a balanced postgraduate education through conferences, courses and journals, I have found the $B D J$ CPD programme very useful for a number of reasons. Primarily it encourages me to read about topics which would not necessarily have been of interest to me - thus broadening my horizons. What I also find useful, though, is the fact that I can print out a log of verifiable CPD hours that satisfy the requirements of the GDC without having to search for all of the course certificates that I have hidden away in safe places never to be found again!

I was thus very annoyed when we were informed at the beginning of the year that each month only one of the articles would appear in full in the Journal. I was in the habit of reading the Journal in an area where I did not have access to a computer and also initially I did not like reading articles from a computer screen. Nevertheless I changed my routine and persevered with reading the online articles. After a while I became used to scrolling through the computer screen and have to confess that I probably digest the articles more accurately than when I read them in the journal! I also find it very useful being able to click on links to read related articles.

So I would like to thank you for encouraging me to make more use of my computer and take advantage of modern technology.

M. Wardle

Ashford, Middlesex

DOI: 10.1038/bdj.2007.698

\section{Gemination or fusion?}

Sir, I read with much interest the very unusual case of a patient who presented with double teeth (BDJ 2007; 202: 508). Although the differentiation between gemination and fusion is very accurately explained, I would like to comment that the authors make the assumption that the case of double teeth was of gemination rather than fusion. As correctly stated, the distinction is made upon the grounds of developmental aetiology with fusion resulting from the union of two separate tooth buds whilst gemination resulting from partial development of two teeth from a single tooth bud., ${ }^{1,2}$ Thus, although the case described is most highly likely due to gemination, this case may be a result of fusion.

I would like to share with your readers another similar case of a healthy 18-year-old who presented with double teeth, complaining of frequent episodes of infection, swelling and irritation associated with an erupted maxillary third molar. Although clinical examination clearly revealed double teeth, radiographic examination failed to accurately demonstrate the anomalous tooth morphology (Fig. 1). The extracted tooth had five separate roots (Figs 2a-c).

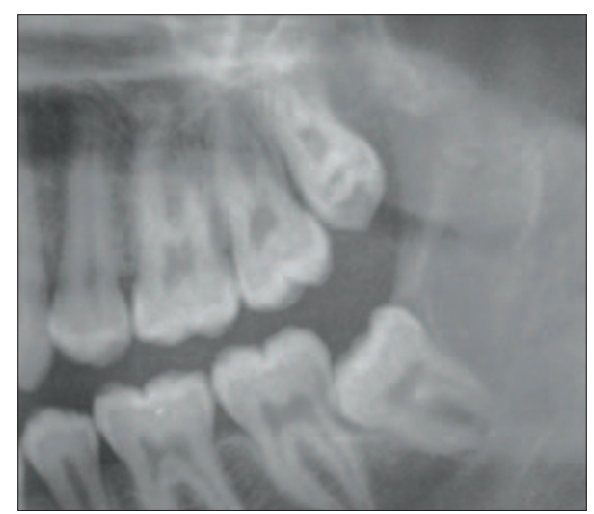

Fig. 1 Dental panoramic radiograph
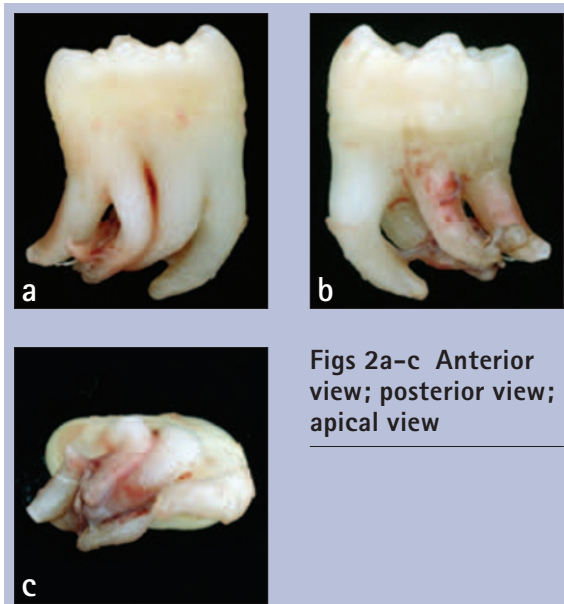

Figs 2a-c Anterior view; posterior view; apical view

The prevalence of double teeth in the primary dentition is $0.5-1.6 \%$; in the permanent dentition it is in the region of $0.1-0.2 \%$. Both sexes are affected with equal frequency. It most commonly involves the anterior dentition and the clinical manifestation of this anomaly varies considerably from a minor notch in the incisal edge of an abnormally wide incisor to the appearance of almost two separate crowns. There may be continuity of hard tissue either between the crowns or roots of the two elements or between both crowns and roots. ${ }^{3}$

Double teeth are not always discernible on radiographs. In this case, the dental panoramic radiograph demonstrates an unusual occlusal surface and cusp morphology but fails to demonstrate the large crown and multi-root structure. This is due to the fact that the tooth was joined in the palatal plane rather than in the buccal. In view of this, my impression is that the double teeth are due to 
fusion between a maxillary third molar with a paramolar rather than due to gemination, although it is impossible to define this with certainty.

The clinical relevance of upper posterior double teeth is in the possibility of unintentionally removing undiagnosed double teeth and/or causing fracture of the maxillary tuberosity upon exodontias. ${ }^{4,5}$ When such a complication is recognised by the general dental practitioner, the maxillary tuberosity should not be removed and the patient should be referred to a specialist unit.

\section{E. Grammatopoulos}

London

1. Soames J V, Southam J C. Oral pathology. 3rd ed. pp 6-7. Oxford: Oxford University Press, 1997.

2. Grover PS, Lorton L. Gemination and twinning in the permanent dentition. Oral Surg Oral Med Oral Pathol 1985; 59: 313-318.

3. Welbury R R. Paediatric dentistry. 2nd ed. pp 277-278. Oxford: Oxford University Press, 2001.

4. Shah N, Bridgman J B. An extraction complicated by lateral and medial pterygoid tethering of a fractured maxillary tuberosity. Br Dent J 2005: 198: 543-544

5. Norman J E, Cannon P D. Fracture of the maxillary tuberosity. Oral Surg Oral Med Oral Pathol 1967; 24: 459-467.

DOI: $10.1038 /$ bdj.2007.699

\section{No overt connection}

Sir, we applaud the British Dental Health Foundation's National Smile Month (13 May - 12 June 2007) oral health campaign but have some serious concerns associated with the sponsorship of this initiative.

Much of the promotional material available to purchase from the BDHF constitutes nothing less than blatant advertising for Golden Vale's Cheestrings. For example, the promotional sticker makes no mention of National Smile Month. Taken away from the dental environment, it has no overt connection with the BDHF's campaign.

Furthermore, there is a link to the Cheestrings website from the National Smile Month web page. This website constitutes a sophisticated advertisement directly aimed at children, with a strap line 'Gotta get some 100\% real cheese'.

We believe that Cheestrings is an inappropriate sponsor for the National Smile Month initiative. This is a processed food and constitutes a very expensive way of obtaining the nutrients and oral health benefits that could be obtained from traditional cheeses such as Cheddar, Edam or Red Leicester as well as a huge range of other foods.

The promotional material states that 'eating Cheestrings as a snack can help reduce tooth decay' which we would argue is a misleading statement because it infers it can repair caries. Furthermore, promotional material does not refer to moderate consumption of Cheestrings. We acknowledge that dairy products are an important part of the nation's diet and have a role in oral health. However, from a holistic public health perspective, we are also mindful of the fact that cheese should be eaten in moderation because it tends to be high in both saturated fat and salt.

With a childhood obesity epidemic looming, the dental profession does not need to be accused of making matters worse by sanctioning high fat processed foods like Cheestrings. Their promotion is in direct conflict with the strenuous efforts that are being made to encourage a multi-disciplinary wider determinants approach to tackling inequalities in oral and general health.

M. Morgan, L. Hunter,

R. Fairchild, K. Stewart Cardiff

Dr Nigel Carter, Chief Executive of the British Dental Health Foundation, responds: We welcome the opportunity to respond to Mrs Morgan et al.'s letter.

None of the resources available for purchase from the Foundation for National Smile Month contain any commercial sponsorship of any kind. The material to which Mrs Morgan refers formed part of a pack of material distributed free of charge by Cheestrings with every National Smile Month order. As such it could be used by practitioners, or not, as they pleased. Many workers in the field of oral health promotion have little or no budget and welcomed any free promotional material.

Golden Vale, the manufacturers of Cheestrings, were one of many corporate sponsors of the campaign this year whose generous support helped us to extend our oral health promotion activities and the reach of this event. Others included Procter and Gamble, Boots, Tesco, Dental Design and HSA. Cheestrings has been accredited by the Foundation's independent accreditation panel who considered a robust submission with supporting peer reviewed papers before approval. Cheestrings is not a processed food but 100\% cheese. The dental benefits of eating a small portion of cheese after a meal, to help neutralise plaque acid, have been well researched and there are many publications on the subject. Cheestrings has the advantage of being individually wrapped and thus portion controlled at $21 \mathrm{~g}$ promoting the moderate intake that Mrs Morgan et al. suggest as a healthy snack.

It should be noted that the Schools Food Trust packed lunch advice recommends cheese as a component of three out of five examples of healthy lunch boxes. The preparation of lunch boxes and snacks for children generates a demand for conveniently packaged, attractively presented nutritious food items. Where convenience takes priority children will very often be presented with several sugar containing snack items and it may be helpful that cheese can be presented as a novelty item.

The Cheestrings literature and website refer to eating a healthy balanced diet and specifically encourage parents to check food packaging for salt and fat content, as well as promoting five portions of fruit and vegetables a day. We accept, however, that this message could be more prominent and we will be taking this up with Golden Vale.

We entirely support the view that dairy products should form part of a balanced diet and constantly promote this position in our media activity. Indeed last year's National Smile Month Campaign theme 'Feed Your Smile' was heavily based on promotion of a healthy balanced diet.

We welcome all feedback on a major campaign such as National Smile Month and take it into account when planning future campaigns to ensure that the health messages the Foundation presents are holistic in approach. DOI: 10.1038/bdj.2007.700 